\title{
Pengaruh Working Capital Turnover (WCT), Current Ratio (CR), dan Total Assets Turnover (TATO) terhadap Profitabilitas
}

\author{
Melia Trie Utami', Gusganda Suria Manda ${ }^{2}$ \\ ${ }^{1,2}$ Universitas Singaperbangsa Karawang \\ e-mail: ${ }^{1}$ melia.trieutami16176@ student.unsika.ac.id, ${ }^{2}$ gusganda.suriamanda@fe.unsika.ac.id

\begin{tabular}{ccc}
\hline Diterima & Direvisi & Disetujui \\
$02-08-2020$ & $21-10-2020$ & $08-03-2021$ \\
\hline
\end{tabular}

\begin{abstract}
Abstrak - Tujuan penelitian ini untuk menguji dan menganalisis pengaruh Working Capital Turnover (WCT), Current Ratio (CR), dan Total Assets Turnover (TATO) terhadap Profitabilitas dengan proksi Return On Assets (ROA) pada perusahaan sub sektor rokok yang terdaftar di Bursa Efek Indonesia (BEI) pertriwulan pada tahun 2014-2019, baik secara parsial maupun simultan. Metode penelitian yang digunakan adalah metode deskriptif verifikatif dengan pendekatan kuantitatif. Sampel dalam penelitian ini menggunakan purposive sampling. Metode statistik yang digunakan adalah metode analisis regresi linear berganda. Hasil penelitian menunjukkan bahwa secara simultan Working Capital Turnover (WCT), Current Ratio (CR), dan Total Assets Turnover (TATO) berpengaruh signifikan terhadap Profitabilitas Return On Assets (ROA). Secara parsial Working Capital Turnover (WCT) berpengaruh negatif signifikan terhadap Profitabilitas Return On Assets (ROA), Current Ratio (CR) tidak berpengaruh terhadap Profitabilitas Return On Assets (ROA), dan Total Assets Turnover (TATO) berpengaruh positif signifikan terhadap Profitabilitas Return On Assets (ROA). Koefisien determinasi yang diperoleh sebesar 0,429 berarti bahwa hanya sebesar 42,9\% Profitabilitas Return On Assets (ROA) dipengaruhi oleh variabel Working Capital Turnover (WCT), Current Ratio (CR), dan Total Assets Turnover (TATO) serta sisanya sebesar $57,1 \%$ dipengaruhi oleh variabel lain.
\end{abstract}

Kata Kunci: Perputaran Modal Kerja (WCT), Rasio Lancar (CR), Perputaran Total Aset (TATO), dan Profitabilitas (ROA)

\begin{abstract}
The purpose of this study was to examine and analyze the effect of Working Capital Turnover (WCT), Current Ratio (CR), and Total Assets Turnover (TATO) on Profitability with the Return On Assets (ROA) proxy on cigarette sub sector companies listed on the Indonesia Stock Exchange (IDX) quarterly in 2014-2019, both partially and simultaneously. The research method used is descriptive verification with quantitative approaches. The sample in this study used purposive sampling. The statistical method used is the method of multiple linear regression analysis. The results showed that the Working Capital Turnover (WCT), Current Ratio (CR), and Total Assets Turnover (TATO) simultaneously had a significant effect on the Return on Assets (ROA) profitability. Partially Working Capital Turnover (WCT) has a significant negative effect on Return on Assets (ROA) profitability, Current Ratio (CR) has no effect on Return on Assets (ROA) Profitability, and Total Assets Turnover (TATO) has a significant positive effect on Return on Profitability Assets (ROA). The coefficient of determination obtained by 0.429 means that only 42.9\% Profitability Return on Assets (ROA) is influenced by Working Capital Turnover (WCT), Current Ratio (CR), and Total Assets Turnover (TATO) and the rest $57.1 \%$ is influenced by other variables.
\end{abstract}

Keywords: Working Capital Turnover (WCT), Current Ratio (CR), Total Assets Turnover (TATO), and Profitability (ROA) 


\section{PENDAHULUAN}

Perusahaan Industri Rokok menjadi salah satu sektor manufaktur nasional yang strategis serta dinilai sebagai sektor padat karya dan bergerak dalam bidang ekspor sehingga mampu menopang pertumbuhan perekonomian untuk negara Indonesia. Industri rokok pada tahun 2018 untuk nilai ekspor rokok dan cerutu tercatat mencapai US\$ 931,6 juta atau mengalami peningkatan sebesar 2,98\% dibanding 2017 yang hanya memperoleh US\$ 904,7 juta. Selain itu subsektor rokok mempunyai peranan dalam mengurangi tingkat pengangguran yang ada di Indonesia, industri ini cukup banyak menyerap tenaga kerja yang tentunya membuka kesempatan kepada masyarakat yang ingin bekerja dengan tersedianya lapangan perkerjaan pada subsektor ini. Menurut kementrian perindustrian mencatat bahwa total tenaga kerja yang diserap oleh sektor industri rokok sebanyak 5,98 juta orang yang terdiri dari 4,28 juta orang adalah pekerja di dalam sektor manufaktur serta sisanya sebanyak 1,7 juta bekerja pada sektor perkebunan. Kemudian industri pada sub sektor rokok juga menjadi penyumbang pada penerimaan kas negara yang cukup signifikan melalui cukai. Sepanjang 2018, penerimaan cukai rokok menembus hingga Rp 153 triliun atau lebih tinggi dibanding perolehan di 2017 sebesar Rp 147 triliun. Penerimaan pada industri rokok pada tahun 2018 mengalami kemajuan, berkontribusi mencapai $95,8 \%$ terhadap cukai nasional (Liputan6, 2019).

Di sisi lain jika dilihat dari kontribusi rokok yang menguntungkan bagi negara, rokok juga mempunyai dampak negatif yaitu adanya bahaya akan rokok bagi kesehatan maka ada beberapa kebijakan yang diambil oleh pemerintah yaitu Peraturan Menteri Kesehatan (Permenkes) nomor 28 tahun 2013 mengenai Pencantuman Peringatan dan Informasi Kesehatan pada Kemasan Produk Tembakau (Rokom, 2013). Serta Peraturan Menteri Keuangan (PMK) Nomor 152/PMK.010/2019 tentang Perubahan Kedua atas PMK Nomor 136/PMK.010/2017 tentang Tarif Cukai Hasil Tembakau (Kompas, 2019).

Setelah adanya kebijakan ini kondisi sub sektor rokok dapat dikatakan sedang mengalami kelesuan dan memprihatinkan, karena ini berimbas pada produksi rokok yang mengalami penurunan yang menyebabkan penjualan ikut menurun. Artinya, apabila penjualan menurun maka akan mengakibatkan berkurangnya profit yang dihasilkan oleh perusahaan.

Faktor yang diduga dapat memengaruhi profitabilitas Return On Asset antara lain Working Capital Turnover (WCT), Current Ratio (CR), dan Total Assets Turnover (TATO). Working Capital Turnover adalah rasio yang menunjukkan kemampuan perusahaan dalam memanfaatkan modal kerja yang dimiliki untuk menghasilkan penjualan. Current Ratio adalah rasio yang menunjukkan kemampuan perusahaan dalam melunasi hutang jangka pendek dengan menjaminkan aset lancar yang dimiliki. Total
Asset Turnover adalah rasio yang menunjukkan kemampuan perusahaan dalam memanfaatkan total aset yang dimiliki untuk menghasilkan penjualan.

Berdasarkan penelitian sebelumnya terdapat perbedaan hasil yaitu:

Menurut Wau (2017) Efisiensi modal kerja (working capital turnover) berpengaruh negatif terhadap profitabilitas, sedangkan menurut Meidiyustiani (2016) Modal kerja (perputaran modal kerja) tidak memiliki pengaruh yang signifikan terhadap profitabilitas. Menurut Meidiyustiani (2016) dan Novita \& Sofie (2015) Likuiditas (current ratio) berpengaruh signifikan positif terhadap profitabilitas, sedangkan menurut Supardi \& Suratno (2016) current ratio tidak berpengaruh terhadap return on assets. Menurut Wikardi \& Wiyani (2017) dan (Supardi \& Suratno (2016) total assets turnover berpengaruh terhadap profitabilitas return on assets, sedangkan menurut Sari \& Budiasih (2014) assets turnover tidak berpengaruh pada profitabilitas.

Dengan adanya research gap dari penelitian sebelumnya yang memiliki hasil berbeda tersebut membuat peneliti tertarik untuk meneliti terdapat atau tidaknya pengaruh serta seberapa besarnya pengaruh masing-masing variabel tersebut yaitu Working Capital unover, Current Ratio, dan Total Assets Turnover terhadap Profitabilitas dengan locus penelitian yang berbeda.

\section{Profitabilitas}

Menurut Kasmir (2014) menyatakan bahwa "Profitabilitas adalah merupakan sebuah rasio yang dijadikan sebagai penilaian dalam mengukur tingkat keefektifitasan manajemen sebuah perusahaan dalam mencapai keuntungan." Profitabilitas dapat dikatakan sebagai hal yang penting untuk sebuah perusahaan dikarenakan untuk melihat seberapa besar perusahaan tersebut dalam mennghasilkan laba selama satu periode. Tingkat profitabilitas yang dihasilkan oleh sebuah perusahaan tersebut dapat memengaruhi para investor untuk berinvestasi. Salah satu cara untuk mengukur tingkat besaran profitabilitas yaitu dengan rasio Return On Assets (ROA).

\section{Return On Assets}

Menurut Miswanto et al., (2017) menyatakan bahwa "Return On Asset adalah sebuah rasio yang digunakan untuk membandingkan hasil usaha yang diperoleh dari operasi perusahaan (net operating income) dengan jumlah investasi atau aktiva yang diunakan dalam menghasilkan keuntungan." Semakin tinggi nilai return on assets maka semakin bagus, artinya perusahaan tersebut dapat memanfaatkan aset yang dimilikinya untuk menghasilkan laba yang maksimal.

\section{Working Capital Turnover (WCT)}

Menurut Kasmir (2014) menyatakan bahwa "Rasio Perputaran Modal Kerja (working capital turnover ratio) merupakan salah satu rasio yang digunakan untuk mengukur serta menilai seberapa efektif modal kerja sebuah perusahaan selama periode tertentu." Apabila perputaran yang dihasilkannya 
tinggi maka akan semakin bagus. Karena artinya perusahaan sudah memanfaatkan modal kerjanya dengan baik dalam menghasilkan penjualan sehingga laba yang didapatkan juga tinggi.

Sehingga apabila perputaran yang dihasilkan tinggi maka akan membuat return on assets juga meningkat.

\section{Current Ratio (CR)}

Menurut Kasmir (2014) menyatakan bahwa "Rasio Lancar (current ratio) adalah suatu rasio yang digunakan untuk mengukur sejauh mana tingkat kesanggupan sebuah perusahaan untuk membayar kewajiban jangka pendeknya atau utang yang segera jatuh tempo pada saat ditagih keseluruhan." Rasio lancar yang tinggi akan membuat kreditur menjadi percaya untuk meminjamkan dananya ke perusahaan karena artinya perusahaan dapat melunasinya dengan menjaminkan aset lancar yang dimiliki. Tetapi itu artinya terlalu banyak aset lancar yang menganggur sehingga kurang efektif dalam mencapai laba.

Sehingga apabila rasio yang dihasilkan tinggi maka akan membuat return on asset menurun.

\section{Total Assets Turnover (TATO)}

Menurut Kasmir (2014) menyatakan bahwa "Rasio Perputaran Total Aset (total assets turnover ratio) adalah sebuah rasio yang digunakan untuk mengukur seberapa besar perputaran keseluruhan aktiva yang dimiliki perusahaan dan mengukur seberapa besar jumlah penjualan yang dihasilkan dari tiap rupiah aktiva yang dimiliki". Semakin tinggi nilai perputaran yang dihasilkan maka akan semakin baik. Karena artinya perusahaan sudah memanfaatkan total asetnya dengan baik dalam menghasilkan penjualan sehingga laba yang didapatkan juga tinggi.

Sehingga apabila perputaran yang dihasilkan tinggi maka akan membuat return on assets juga meningkat. METODOLOGI PENELITIAN

Data yang digunakan penelitian ini adalah data sekunder berupa laporan keuangan. Metode yang digunakan adalah metode analisis deskriptif, verifikatif dengan pendekatan kauntitatif menggunakan regresi linier berganda.

Penelitian ini menggunakan tiga variabel independen yaitu working capital turnover, current ratio, total assets turnover dan satu variabel dependen yaitu profitabilitas dengan proksi return on assets. Sebagaimana terlihat pada tabel berikut:

Tabel 1. Variabel Penelitian

\begin{tabular}{|l|l|l|l|}
\hline No & Variabel & Pengukuran & Skala \\
\hline 1 & $\begin{array}{l}\text { Working } \\
\text { Capital } \\
\text { Turnover } \\
\text { Rahmawati, } \\
\text { et al(2016) }\end{array}$ & Penjualan/(Aktiva & Lancar-Hutang Lancar) \\
\hline 2 & $\begin{array}{l}\text { Current } \\
\text { Ratio } \\
\text { Wartono } \\
\text { (2018) }\end{array}$ & Aktiva lancar/Hutang & Rasio \\
\hline 3 & $\begin{array}{l}\text { Total Assets } \\
\text { Turnover } \\
\text { Wikardi \& } \\
\text { Wiyani } \\
\text { (2017) }\end{array}$ & Penjualan/Total Aset & Rasio \\
\hline
\end{tabular}

\begin{tabular}{|l|l|l|l|}
\hline 4 & $\begin{array}{l}\text { Return On } \\
\text { Assets } \\
\end{array}$ & Laba Bersih/Total Aset & Rasio \\
& $\begin{array}{l}\text { Miswanto } \\
\text { (2017) }\end{array}$ & & \\
\hline
\end{tabular}

Sumber: dari beberapa sumber

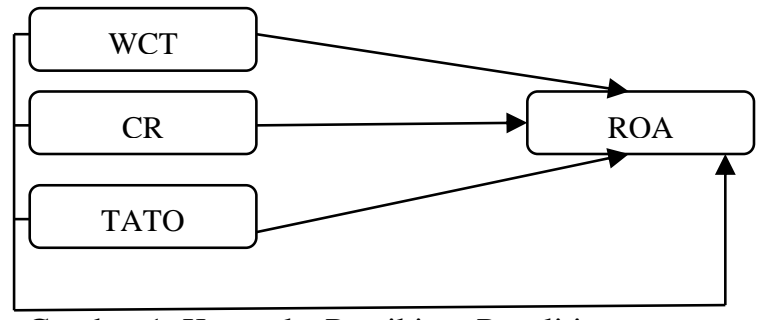

Gambar 1. Kerangka Pemikiran Penelitian

Sumber: Dikaji dari beberapa sumber

H1:WCT berpengaruh terhadap ROA

$\mathrm{H} 2$ :CR berpengaruh terhadap ROA

H3:TATO berpengaruh terhadap ROA

H4:WCT, CR, dan TATO secara simultan berpengaruh terhadap ROA

\section{Uji Asumsi Klasik}

1. Uji Normalitas

Menurut Ghozali (2016) uji normalitas digunakan untuk menguji apakah dalam suatu model regresi, variabel pengganggu atau residual berdistribusi normal atau tidak. Model regresi yang dikatakan baik apabila data berdistribusi normal atau mendekati normal. Untuk mengetahui normalitasnya suatu data dapat dilakukan melalui pengujian yaitu Uji Kolmogrof Smirnov, dalam uji ini apabila nilai signifikan yang didapat $>0.05$ maka data berdistribusi normal sedangkan apabila nilai signifikan yang didapat $<0.05$ maka data berdistribusi tidak normal.

2. Uji Multikolinearitas

Menurut Ghozali (2016) uji multikolinearitas digunakan untuk menguji apakah model regresi mempunyai korelasi antar variabel bebas (independen). Model regresi yang baik seharusnya tidak terdapat korelasi antar variabel bebas atau tidak terjadi multikolinearitas. Multikolinearitas dapat dilihat dari nilai tolerance dan variance inflation factor (VIF). Menunjukkan adanya multikolinearitas adalah apabila nilai tolerence $<0.10$ atau sama dengan nilai VIF > 10 .

\section{Uji Heteroskedastisitas}

Menurut Ghozali (2016) uji heteroskedasitas digunakan untuk menguji apakah dalam model regresi terdapat ketidaksamaan variance dari residual satu pengamatan ke pengamatan lain. Salah satu cara yang digunakan agar dapat diketahui ada atau tidaknya gejala heteroskedastisitas dengan melihat pada grafik scatter plot. Jika terdapat pola tertentu seperti titiktitik yang membentuk pola tertentu serta teratur (bergelombang, melebar, kemudian menyempit) maka mengindikasikan telah terjadinya heteroskedastisitas. Namun, jika tidak terdapat pola yang jelas maka dapat dikatakan tidak terjadi gejala heteroskedastisitas.

4. Uji Autokorelasi 
Menurut Ghozali (2016) autokorelasi dapat muncul karena observasi yang berurutan sepanjang waktu yang berkaitan satu sama lainnya. Permasalahan ini muncul karena residual tidak bebas pada satu observasi ke obseravsi lainnya.

\section{Metode Analisis Penelitian}

\section{Model Penelitian}

Analisis verifikatif yang digunakan pada penelitian ini adalah analisis regresi linier berganda. Regresi linier berganda digunakan untuk mengetahui besarnya arah koefisien atau hubungan antara variabel bebas dengan variabel terikat. Persamaan umum yang ddigunakan dalam regresi linier berganda yaitu:

$$
\begin{array}{|l}
\mathrm{Y}=\mathrm{a}+\mathrm{b} 1 \mathrm{X} 1+\mathrm{b} 2 \\
\text { Sugiyono (2018) }
\end{array}
$$

Keterangaan:

$\mathrm{Y}=$ Profitabilitas

$\mathrm{a}=$ Konstanta atau harga $\mathrm{Y}$ bila $\mathrm{X}=0$

b1, b2, b3= Angka atau arah koefisien regresi, yang menunjukkan angka peningkatan ataupun penurunan variabel dependen yang didasarkan pada variabel independen.

$\mathrm{X} 1=$ Working Capital Turnover

$\mathrm{X} 2=$ Current Ratio

X3 = Total Assets Turnover

$\mathrm{e}=$ Tingkat kesalahan pengganggu

2. Pengujian Hipotesis Secara Parsial

Menurut Ghozali (2016) uji statistik t ini adalah suatu pengujian yang dilakukan agar dapat diketahui seberapa besar pengaruh masing-masing variabel independen yang digunakan dalam penelitian ini terhadap variabel dependen secara parsial. Pengambilan keputusan ini ditentukan berdasarkan hasil perbandingan antara nilai $t$ hasil perhitungan ( $\left.t_{\text {hitung }}\right)$ dengan nilai $\left(t_{\text {tabel }}\right)$, dengan tingkat signifikan $5 \%$.

a. Jika nilai $\left(\mathrm{t}_{\text {hitung }}\right)>\left(\mathrm{t}_{\text {tabel }}\right)$ maka $\mathrm{HO}$ ditolak dan $\mathrm{Ha}$ diterima, yang berarti variabel independen berpengaruh terhadap nilai variabel dependen.

b. Jika nilai $\left(\mathrm{t}_{\text {hitung }}\right)<\left(\mathrm{t}_{\text {tabel }}\right)$ maka $\mathrm{HO}$ diterima dan $\mathrm{Ha}$ ditolak yang berarti variabel independen tidak berpengaruh terhadap nilai variabel dependen.

3. Pengujian Hipotesis Secara Simultan

Menurut Ghozali (2016) uji statistik F adalah suatu pengujian untuk mengethui seberapa besar pengaruh semua variabel independen yang digunakan dalam penelitian secara simultan atau bersama-sama terhadap variabel dependen. Pengambilan keputusan ini ditentukan berdasarkan hasil perbandingan antara nilai $\mathrm{F}$ hasil perhitungan $\left(\mathrm{F}_{\text {hitung }}\right)$ dengan nilai $\left(\mathrm{F}_{\text {tabel }}\right)$, dengan tingkat signifikan $5 \%$.

a. Jika nilai $\left(\mathrm{F}_{\text {hitung }}\right)>\left(\mathrm{F}_{\text {tabel }}\right)$ maka $\mathrm{HO}$ ditolak dan $\mathrm{Ha}$ diterima, yang berarti semua variabel independen berpengaruh terhadap nilai variabel dependen.

b. Jika nilai $\left(\mathrm{F}_{\text {hitung }}\right)<\left(\mathrm{F}_{\text {tabel }}\right)$ maka $\mathrm{HO}$ diterima dan $\mathrm{Ha}$ ditolak, yang berarti semua variabel independen tidak berpengaruh terhadap nilai variabel dependen.

\section{HASIL DAN PEMBAHASAN}

\section{Analisis Deskriptif}

Tabel 2. Hasil Analisis Deskriptif

\begin{tabular}{|l|l|l|l|l|l|}
\hline \multicolumn{6}{|l|}{ Decriptive Statistics } \\
\hline Keterangan & N & Min & Max & Mean & $\begin{array}{l}\text { Std. } \\
\text { Deviation }\end{array}$ \\
\hline WCT & 96 & $-3,57$ & 97,53 & 4,0280 & 10,31186 \\
\hline CR & 96 & 0,48 & 17,27 & 2,7889 & 1,97196 \\
\hline TATO & 96 & 0,05 & 2,84 & 0,9700 & 0,56817 \\
\hline ROA & 96 & $-20,80$ & 35,87 & 5,8277 & 10,48722 \\
\hline $\begin{array}{l}\text { Valid N } \\
\text { (listwise) }\end{array}$ & 96 & & & & \\
\hline
\end{tabular}

Sumber : Hasil data olahan SPSS

Berdasarkan tabel 1. Hasil analisis deskriptif pada variabel Working Capital Turnover menunjukan nilai minimal sebesar $(-3,57)$ dan nilai maksimumnya sebesar 97,53 serta nilai rata-rata yang diperoleh sebesar 4,0280 dan standar deviasinya sebesar 10,31186. Pada variabel Current Ratio menunjukan nilai minimal sebesar 0,48 dan nilai maksimumnya sebesar 12,27 serta nilai rata-rata yang diperoleh sebesar 2,7889 dan standar deviasinya sebesar 1,97196. Pada variabel Total Assets Turnover menunjukan nilai minimal sebesar 0,05 dan nilai maksimumnya sebesar 2,84 serta nilai rata-rata yang diperoleh sebesar 0,9700 dan standar deviasinya sebesar 0,56817. Dan pada variabel Return On Assets menunjukan nilai minimal sebesar $(-20,80)$ dan nilai maksimumnya sebesar 35,87 serta nilai rata-rata yang diperoleh sebesar 5,8277 dan standar deviasinya sebesar 10,48722.

Tabel 3. Hasil Uji Normalitas Dengan Kolmogrov Smirnov Setelah Outlier

\begin{tabular}{|c|c|c|}
\hline \multicolumn{3}{|c|}{ One-Sample Kolmogrov-Smirnov Test } \\
\hline & & $\begin{array}{l}\text { Untandardized } \\
\text { Residual }\end{array}$ \\
\hline \multicolumn{2}{|l|}{$\mathbf{N}$} & 76 \\
\hline \multirow[t]{2}{*}{$\begin{array}{l}\text { Normal } \\
\text { Parameters }{ }^{\text {a.b }}\end{array}$} & Mean & $0 \mathrm{E}-7$ \\
\hline & $\begin{array}{l}\text { Std. } \\
\text { Deviation }\end{array}$ & 5,65190477 \\
\hline \multirow[t]{3}{*}{$\begin{array}{l}\text { Most Extreme } \\
\text { Differences }\end{array}$} & Absolute & 0,126 \\
\hline & Positive & 0,109 \\
\hline & Negative & $-0,126$ \\
\hline \multicolumn{2}{|l|}{ Test Statistics } & 1,097 \\
\hline \multicolumn{2}{|l|}{ Asymp. Sig. (2-tailed) } & 0,180 \\
\hline \multicolumn{3}{|c|}{ a. Test Distribution is Normal } \\
\hline \multicolumn{3}{|c|}{ b. Calculated From Data } \\
\hline \multicolumn{3}{|c|}{$\begin{array}{l}\text { Berdasarkan Tabel } 2 \text { pada uji normalitas } \\
\text { iketahui bahwa Uji One-Sample Kolmogrov Smirnov } \\
\text { est yang diperoleh nilai Asymp.Sig (2-tailed) sebesar } \\
\text { 180. Karena nilai } 0.180>\text { dari } 0.05 \text {, maka dapat } \\
\text { isimpulkan bahwa data berdistribusi normal. } \\
\text { abel 4. Hasil Uji Multikolinearitas }\end{array}$} \\
\hline Coefficients & & \\
\hline
\end{tabular}




\begin{tabular}{|l|l|l|}
\cline { 2 - 3 } & \multicolumn{2}{|l|}{$\begin{array}{l}\text { Collinearity } \\
\text { Statistics }\end{array}$} \\
\cline { 2 - 3 } & Tolerance & VIF \\
\hline Constant & & \\
\hline WCT & 0,194 & 5,147 \\
\hline CR & 0,481 & 2,078 \\
\hline TATO & 0,261 & 3,831 \\
\hline \multicolumn{2}{|l}{ a. Dependent Variable : Return On Assets } \\
\hline
\end{tabular}

Sumber : Hasil data olahan SPSS

Berdasarkan Tabel 3 pada uji multikolinearitas diketahui bahwa nilai Tolerance yang $>0,10$ serta nilai VIF yang $<10$. Maka dapat disimpulkan tidak terjadi Multikolinearitas.

Scatterplot

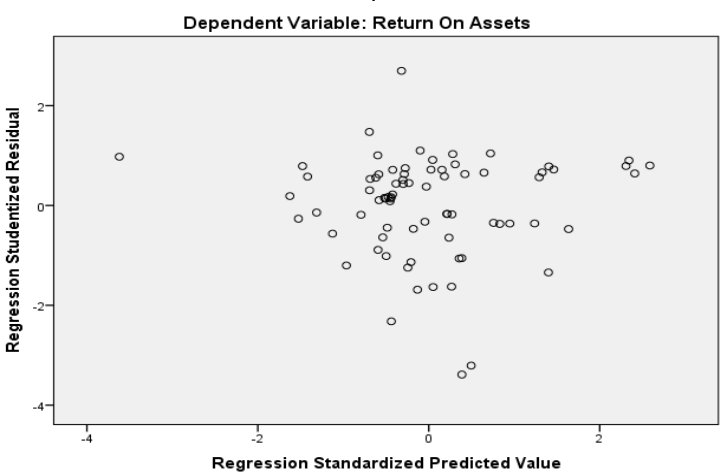

Gambar 2. Hasil Uji Heteroskedastisitas

Sumber : Hasil data olahan SPSS

Berdasarkan Tabel 4 hasil uji heteroskedastisitas dapat dilihat bahwa titik-titik menyebar diatas dan dibawah angka 0 pada sumbu $\mathrm{Y}$ dan tidak ada pola yang jelas. Sehingga dapat disimpulkan bahwa model regresi dalam penelitian ini bebas dari heteroskedastisitas.

Tabel 5. Hasil Uji Autokorelasi

\begin{tabular}{|c|c|}
\hline \multicolumn{2}{|l|}{ Runs Test } \\
\hline & Unstandardized Residual \\
\hline Test Value & 1,00923 \\
\hline Cases < Test Value & 38 \\
\hline Cases $>=$ Test Value & 38 \\
\hline Total Cases & 76 \\
\hline Number of Runs & 45 \\
\hline $\mathrm{Z}$ & 1,386 \\
\hline Asymp. Sig. (2-tailed) & 0,166 \\
\hline
\end{tabular}

Sumber : Hasil data olahan SPSS

Berdasarkan Tabel 5 hasil uji autokorelasi diperoleh hasil dari uji run-test sebesar 0,166 dilihat pada nilai Asymp. Sig. (2-tailed), yang artinya nilai yang dihasilkan jauh lebih besar dari nilai signifikan pada 0,05 yang berarti hipotesis nol diterima. Sehingga dapat disimpulkan bahwa tidak terjadi autokorelasi antara nilai residual.

\section{Analisis Verifikatif}

Tabel 6. Hasil Uji Regresi Linear Berganda

\begin{tabular}{|l|l|l|}
\hline \multirow{2}{*}{ Coefficients } & \multicolumn{2}{l|}{$\begin{array}{l}\text { Unstandardized } \\
\text { Coefficients }\end{array}$} \\
\cline { 2 - 3 } & B & Std. Error \\
\hline Constant & 4,897 & 3,575 \\
\hline WCT & $-5,539$ & 1,142 \\
\hline CR & $-2,105$ & 1,182 \\
\hline TATO & 21,420 & 3,156 \\
\hline a. Dependent Variable : Return On Assets \\
\hline
\end{tabular}

Sumber : Hasil data olahan SPSS

Dari hasil Tabel 6 regresi linear berganda didapatkan nilai kontanta regresi 4,897 dengan nilai koefisien untuk variabel WCT sebesar -5,539, CR sebesar -2,105, dan TATO sebesar 21,420.

ROA $=4,897+(-5,539$ WCT $)+(-2,105 \mathrm{CR})+21,420$ TATO.

Tabel 7. Hasil Uji Parsial

\begin{tabular}{|c|c|c|}
\hline \multicolumn{3}{|c|}{ Coefficients } \\
\hline Model & $\mathrm{T}$ & Sig. \\
\hline Constant & 1,370 & 0,175 \\
\hline WCT & $-4,851$ & 0,000 \\
\hline $\mathrm{CR}$ & $-1,780$ & 0,079 \\
\hline TATO & 6,786 & 0,000 \\
\hline a. Depend & ROA & \\
\hline
\end{tabular}

Sumber : Hasil data olahan SPSS

Nilai $t_{\text {tabel }}$ yang diperoleh sebesar 1,993 didapat dari $\mathrm{t}_{\text {tabel }}=\mathrm{t}(0,025 ; 72)=1,993$. Hasil uji parsial atas variabel WCT didapatkan nilai $t_{\text {hitung }}$ sebesar $-4,851$ dan nilai sig. 0,000. Nilai $t_{\text {hitung }}-4,851>t_{\text {tabel }} 1,993$ serta nilai sig. $0,000<0,05$. Maka hipotesis dinyatakan diterima. Variabel CR didapatkan nilai thitung sebesar 1,780 dan nilai sig. 0,079 . Nilai $t_{\text {hitung }}-1,780<\mathrm{t}_{\text {tabel }}$ 1,993 serta nilai sig. 0,079>0,05. Maka hipotesis dinyatakan ditolak. Variabel TATO didapatkan nilai $t_{\text {hitung }}$ sebesar 6,786 dan nilai sig. 0,000. Nilai thitung $6,786>t_{\text {tabel }} 1,993$ serta nilai sig. $0,000<0,05$. Maka hipotesis dinyatakan diterima.

Tabel 8. Hasil Uji Simultan

\begin{tabular}{|l|l|l|}
\hline ANOVA $^{\mathrm{a}}$ & F & Sig. \\
\hline Model & 18,026 & $0,000^{\mathrm{b}}$ \\
\hline Regression & & \\
\hline Residual & & \\
\hline Total & & \\
\hline \multicolumn{3}{|l|}{ a. Dependent Variable : Return On Assets } \\
\hline
\end{tabular}


b. Predictors: (Constant), Total Assets Turnover, Current Ratio, Working Capital Turnover

Sumber : Hasil data olahan SPSS

Nilai $F_{\text {tabel }}$ yang diperoleh sebesar 1,993 didapat dari $\mathrm{F}_{\text {tabel }}=\mathrm{F}(3 ; 73)=2,73$. Hasil uji simultan yang dilakukan pada WCT, CR, dan TATO terhadap ROA didapatkan nilai $F_{\text {hitung }}$ sebesar 18,026 serta nilai sig. 0,000 . Yang artinya nilai $F_{\text {hitung }} 18,026>$ nilai $F_{\text {tabel }}$ 2,73 serta nilai sig. $0,000<0,05$ sehingga hipotesis diterima.

Tabel 9. Hasil Koefisien Determinasi

\begin{tabular}{|l|l|l|l|}
\hline \multicolumn{3}{|l|}{ Model Summary } \\
\hline Model & R & R Square & Adjusted R Square \\
\hline 1 & $0,655^{\mathrm{a}}$ & 0,429 & 0,405 \\
\hline $\begin{array}{l}\text { a. Predictors : (Constant), Total Assets Turnover, } \\
\text { Current Ratio, Working Capital Turnover }\end{array}$ \\
\hline \multicolumn{4}{|l}{ b. Dependent Variable : Return On Assets } \\
\hline
\end{tabular}

Sumber : Hasil data olahan SPSS

Pada tabel 9 didapatkan nilai koefisien determinasi atau $\mathrm{R}^{2}$ sebesar 0.429 atau sebesar $42,9 \%$. Hal ini menunjukkan bahwa variabel yang diteliti yaitu WCT, CR dan TATO berpengaruh sebesar $42,9 \%$ terhadap ROA. Sedangkan sisanya yaitu $57,1 \%$ dipengaruhi oleh variabel lain yang tidak diteliti dalam penelitian ini

Berdasarkan hasil pengujian yang telah dilakukan pada WCT maka diperoleh nilai $t_{\text {hitung }}$ sebesar -4,851 dan nilai $t_{\text {tabel }}$ yaitu sebesar 1,993. Sehingga jika dibandingkan nilai $t_{\text {hitung }}-4,851>$ nilai $\mathrm{t}_{\text {tabel }} 1,993$. Serta nilai signifikansi sebesar 0,000 lebih kecil dari 0,05. Sehingga sudah dapat disimpulkan $\mathrm{H}_{0}$ ditolak dan $\mathrm{H}_{1}$ diterima. Selain itu, pada koefisien regresi variabel WCT memiliki nilai yang negatif (-) yaitu sebesar $(-5,539)$. Hal ini menunjukkan bahwa terdapat hubungan tidak searah antara WCT dengan ROA yang apabila terjadi kenaikan pada WCT sebesar satu-satuan maka akan diikuti dengan menurunnya ROA sebesar sebesar $(-5,539 \%)$.

WCT menggambarkan bagaimana suatu perusahaan dalam memanfaatkan serta mengelola modal kerja yang dimilikinya. Perusahaan yang memanfaatkan modal kerjanya dengan baik dalam mencapai penjualan akan menyebabkan perputaran modal kerja yang tinggi. Semakin tinggi perputaran modal kerja maka akan semakin baik karena dapat meningkatkan laba pada perusahaan tersebut dan membuat profitabilitas atas return on assets juga mengalami peningkatan.

Tetapi dalam penelitian ini WCT memiliki hubungan tidak searah dilihat dari uji regresi yang bernilai negatif (-) yang apabila WCT ini mengalami peningkatan maka aka menyebabkan penurunan pada profitabilitas ROA. Hal tersebut dikarenakan jumlah WCT yang besar menyebabkan tingginya bebanbeban yang terdapat pada pos beban operasional seperti beban penjualan, serta beban umum dan administrasi yang dibebankan pada aktvitas operasi yang dilakukan oleh sebuah perusahaan, sehingga perusahaan yang tadinya mendapatkan laba kotor tetapi menjadi mengalami penurunan laba atau bahkan kerugian setelah dibebankannya beban operasional dan inilah yang membuat tingkat profitabilitas atas ROA mengalami penurunan.

Dengan demikian, didapat kesimpulan bahwa terdapat pengaruh negatif yang signifikan pada WCT terhadap ROA. Hal ini mengindikasikan bahwa peningkatan WCT selama periode penelitian mempengaruhi ROA yang dihasilkan. Hasil peneitian ini sejalan dengan hasil penelitian yang dilakukan oleh Wau (2017) yang mengemukakan bahwa "Working Capital Turnover berpengaruh negatif terhadap profitabilitas."

Berdasarkan hasil pengujian yang telah dilakukan pada CR maka diperoleh nilai $t_{\text {hitung }}$ sebesar $-1,780$ dan nilai $t_{\text {tabel }}$ yaitu sebesar 1,993. Sehingga jika dibandingkan nilai $t_{\text {hitung }}-1,780<$ nilai $t_{\text {tabel }} 1,993$. Serta nilai signifikansi sebesar 0,079 lebih besar dari 0,05. Sehingga sudah dapat disimpulkan $\mathrm{H}_{0}$ diterima dan $\mathrm{H}_{2}$ ditolak. Selain itu, pada koefisien regresi variabel CR memiliki nilai yang negatif (-) yaitu sebesar $(-2,105)$. Hal ini menunjukkan bahwa terdapat hubungan tidak searah antara CR dengan ROA yang apabila terjadi kenaikan pada CR sebesar satu-satuan maka akan diikuti dengan menurunnya ROA sebesar sebesar $(-2,105)$.

Dalam penelitian ini CR memiliki hubungan tidak searah dilihat dari uji regresi yang bernilai negatif (-) yang apabila CR ini mengalami peningkatan maka akan menyebabkan penurunan pada profitabilitas ROA. Hal tersebut dikarenakan CR yang terlalu besar tidak baik pengaruhnya terhadap ROA. Meskipun apabila dilihat dari kemampuan sebuah perusahaan dalam melunasi hutang jangka pendeknya dapat dikatakan bagus karena kemungkinan dalam terjadinya gagal bayar atas hutang jangka pendek atau hutang yang jatuh tempo tersebut semakin kecil. Tetapi disisi lain itu artinya bahwa terdapat aktiva lancar yang mengganggur seperti kas, piutang, dan persediaan.

Dengan demikian, didapat kesimpulan bahwa tidak terdapat pengaruh pada CR terhadap ROA. Hasil peneitian ini sejalan dengan hasil penelitian yang dilakukan oleh Supardi \& Suratno (2016) yang mengemukakan bahwa "Current Ratio tidak berpengaruh terhadap return on assets."

Berdasarkan hasil pengujjian yang telah dilakukan pada TATO maka diperoleh nilai thitung sebesar 6,786 dan nilai $t_{\text {tabel }}$ yaitu sebesar 1,993. Sehingga jika dibandingkan nilai $t_{\text {hitung }} 6,786>$ nilai $\mathrm{t}_{\text {tabel }}$ 1,993. Serta nilai signifikansi sebesar 0,000 lebih kecil dari 0,05. Sehingga sudah dapat disimpulkan $\mathrm{H}_{0}$ ditolak dan $\mathrm{H}_{3}$ diterima. Selain itu, pada koefisien regresi variabel total assets turnover memiliki nilai yang positif (+) yaitu sebesar $21,420 \%$. Hal ini menunjukkan bahwa terdapat hubungan searah antara TATO dengan ROAyang apabila terjadi kenaikan 
pada TATO sebesar satu-satuan maka akan diikuti dengan ROA sebesar sebesar $21,420 \%$.

Dalam penelitian ini TATO memiliki hubungan searah dilihat dari uji regresi yang bernilai positif (+) yang apabila TATO ini mengalami peningkatan maka akan menyebabkan kenaikan pada profitabilitas ROA. Hal tersebut menunjukkan bahwa perusahaan sudah dapat mengelola total aset yang dimiliki secara efisien, sehingga perusahaan dapat menghasilkan penjualan yang maksimal atas total aset yang dimiliki dan nantinya perusahaan akan memperoleh laba yang tinggi karena penjualan yang tinggi. Semakin tinggi peputaran pada total aset ini menjadikannya semakin bagus, itu akan membuat ROA juga meningkat.

Dengan demikian, didapat kesimpulan bahwa terdapat pengaruh positif yang signifikan pada TATO terhadap ROA. Hal ini mengindikasikan bahwa peningkatan TATO selama periode penelitian mempengaruhi ROA yang dihasilkan. Hasil peneitian ini sejalan dengan hasil penelitian yang dilakukan oleh Wikardi \& Wiyani (2017) dan Supardi \& Suratno (2016) yang mengemukakan bahwa "Total Assets Turnover berpengaruh terhadap profitabilitas Return On Assets."

Berdasarkan hasil pengujian yang telah dilakukan maka diperoleh nilai $F_{\text {hitung }}$ yaitu sebesar 18,026 dan nilai $F_{\text {tabel }}$ yaitu sebesar 2,73. Sehingga jika dibandingkan nilai $F_{\text {hitung }} 18,026>$ nilai $F_{\text {tabel }} 2,73$. Serta nilai signifikansi sebesar 0,000 lebih kecil dari 0,05. Sehingga sudah dapat disimpulkan $\mathrm{H}_{0}$ ditolak dan $\mathrm{H}_{4}$ diterima. Yang berarti bahwa terdapat pengaruh antara WCT, CR, dan TATO terhadap ROA. Selain itu, didapatkan nilai koefisien determinasi atau $\mathrm{R}^{2}$ sebesar 0.429 atau sebesar $42,9 \%$. Hal ini menunjukkan bahwa variabel yang diteliti yaitu WCT, CR, dan TATO berpengaruh sebesar $42,4 \%$ terhad ap ROA. Sedangkan sisanya yaitu $57,1 \%$ dipengaruhi oleh variabel lain yang tidak diteliti dalam penelitian ini.

Hasil penelitian ini sejalan dengan hasil penelitian yang dilakukan oleh Ginting (2018) mengemukakan bahwa "Secara bersama-sama Current Ratio, Working Capital Turnover dan Total Assets Turnover memiliki pengaruh yang signifikan dan positif terhadap Return On Assets.

\section{KESIMPULAN}

Berdasarkan penelitian dan pembahasan yang dilakukan oleh penulis, maka dapat diambil beberapa kesimpulan, pengujian secara parsial yaitu terdapat pengaruh negatif signifikan pada Working Capital Turnover terhadap Return On Assets, tidak terdapat pengaruh pada Current Ratio terhadap Return On Assets, terdapat pengaruh positif signifikan pada Total Assets Turnover terhadap Return On Assets. Dan secara parsial diketahui bahwa terdapat pengaruh antara Working Capital turnover, Current Ratio, dan Total Assets Turnover terhadap Return On Assets.

Penelitian ini diharapkan agar dapat berguna bagi pihak terkait seperti pihak perusahaan yang terdapat pada sub sektor rokok agar lebih dapat memanfaatkan modal kerja yang dimilikinya, serta agar memanfaatkan aktiva lancar yang ada agar mencapai penjualan yang maksimal sehingga laba yang dihasilkan juga maksimal. Serta lebih dapat menekan biaya operasional agar laba mengalami peningkatan.

Disarankan untuk peneliti selanjutnya agar dapat menambah variabel diluar dari yang telah diteliti agar hasilnya lebih dapat diketahui seberapa besar pengaruhnya terhadap variabel yang akan diteliti.

\section{REFERENSI}

Ghozali, I. (2016). Aplikasi Analisis Multivariete IBM SPSS. Semarang: Universitas Diponegoro.

Ginting, W. A. (2018). ANALISIS PENGARUH CURRENT RATIO, WORKING CAPITAL TURNOVER, DAN TOTAL ASSET TURNOVER TERHADAP RETURN ON ASSET. Valid Jurnal Ilmiah. 15(2). 163-172. http://journal.stieamm.ac.id/index.php/valid/art icle/view/73.

Kasmir. (2014). Analisis Laporan Keuangan, Edisi Satu, Cetakan Ketujuh. Jakarta: Raja Grafindo Persada.

Kompas. 2019. Siap-siap Inilah Daftar Tarif dan Harga yang Bakal Naik pada 2020. https://www.kompas.com/tren/read/2019/12/30/ 112641565/siap-siap-ini-daftar-tarif-dan-hargayang-bakal-naik-pada-2020?page $=$ all

Liputan6. 2019. Menperin Ungkap Kontribusi Industri Hasil Tembakau Ke Negara. https://www.liputan6.com/bisnis/read/3925859/ menperin-ungkap-kontribusi-industri-hasiltembakau-ke-negara

Meidiyustiani, R. (2016). Pengaruh Modal Kerja, Ukuran Perusahaan, Pertumbuhan Penjualan, Dan Likuiditas Terhadap Profitabilitas Pada Perusahaan Manufaktur Sektor Industri Barang Konsumsi Yang Trdaftar Di Bursa Efek Indonesia (BRI) Periode Tahun 2010-2014. Jurnal Akuntansi Dan Keuangan. 5(2). 41-59. https://journal.budiluhur.ac.id/index.php/akeu/a rticle/view/405

Miswanto, Abdullah, yanuar R., Suparti, S., \& All, E. (2017). Pengaruh Efisiensi Modal Kerja, Pertumbuhan Penjualan Dan Ukuran Perusahaan Terhadap Profitabilitas Perusahaan. Journal of Chemical Information and Modeling . 24(2)

119-135. https://www.unisbank.ac.id/ojs/index.php/fe3/a rticle/view/5878 
Novita, B. A., \& Sofie, S. (2015). PENGARUH STRUKTUR MODAL DAN LIKUIDITAS TERHADAP PROFITABILITAS. Jurnal Akuntansi Trisakti. 2(1). 13-28. https://doi.org/10.25105/jat.v2i1.4829

Rahmawati, S. Salim, M. A. M. K. A. (2016). NGARUH LIKUIDITAS, PERTUMBUHAN PENJUALAN, PERPUTARAN MODAL KERJA, UKURAN PERUSAHAAN DAN LEVERAGE TERHADAP PROFITABILITAS PERUSAHAAN (Studi pada Perusahaan Manufaktur yang Terdaftar pada BEI pada Tahun 2014 -2016). E-Jurnal Riset Manajemen Unisma. 7(10). 93-107. http://riset.unisma.ac.id/index.php/jrm/article/v iew/1257/0

Rokom. 2013. Permenkes 28/2013: Pencantuman Perngatan dan Informasi Kesehatan pada Kemasan Rokok http://sehatnegeriku.kemkes.go.id/baca/rilismedia/20130601/198034/permenkes-282013pencantuman-peringatan-dan-informasikesehatan-pada-kemasan-rokok/

Sari, N. M. V., \& Budiasih, I. G. A. N. (2014). Pengaruh Debt To Equity Ratio, Firm Size, Inventory Turnover dan Assets Turnover Pada Profitabilitas. E-Jurnal Akuntansi Universitas Udayana. 6(2). 261-273. https://ojs.unud.ac.id/index.php/Akuntansi/artic le/view/7930
Sugiyono. (2018). Metode Penelitian Kombinasi (mixed Methods). Bandung: Alfabeta

Supardi, H., \& Suratno, H. (2016). Pengaruh Current Ratio , Debt To Asset Ratio , Total Asset Turnover Dan Inflasi TERHADAP Return On Asset. Jurnal Ilmiah Akuntansi Fakultas Ekonomi. 2(1). 71-27

Wartono, T. (2018). Pengaruh Current Ratio dan Debt To Equity Ratio Terhadap Return On Asset (Studi pada PT Astra Internasional Tbk). Jurnal Kreatif. 6(2). 78-97. http://dx.doi.org/10.32493/jk.v6i2.y2018.p7897

Wau, R. (2017). Analisis Efektifitas Modal Kerja Dan Pengaruhnya Terhadap Profitabilitas. Journal of Business $\quad$ Studies. 2(1). 16-27. http://journal.uta45jakarta.ac.id/index.php/jbsut a/article/view/786/504

Wikardi, L. D., \& Wiyani, N. T. (2017). Pengaruh Debt to Equity Ratio , Firm Size, Inventory Turnover, Assets Turnover dan Pertumbuhan Penjualan Terhadap Profitabilitas. Jurnal Online Insan Akuntan. 2(1). 99-118. http://ejournal-

binainsani.ac.id/index.php/JOIA/article/view/4 34 